\title{
Deficiency and haploinsufficiency of histone macroH2A1.1 in mice recapitulate hematopoietic defects of human myelodysplastic syndrome
}

Oxana Bereshchenko ${ }^{1 *}$, Oriana Lo Re ${ }^{2,3}$, Fedor Nikulenkov ${ }^{2,3}$, Sara Flamini ${ }^{1}$, Jana Kotaskova ${ }^{4,5}$, Tommaso Mazza ${ }^{6}$, Marguerite-Marie Le Pannérer ${ }^{7,8}$, Marcus Buschbeck ${ }^{7,8}$, Cesarina Giallongo ${ }^{9}$, Giuseppe Palumbo ${ }^{10}$, Giovanni Li Volti ${ }^{11}$, Valerio Pazienza ${ }^{12}$, Libor Cervinek ${ }^{5}$, Carlo Riccardi ${ }^{1}$, Lumir Krejci²,3, Sarka Pospisilova ${ }^{4,5}$, A. Francis Stewart ${ }^{13}$ and Manlio Vinciguerra ${ }^{2 *}$ (D)

\begin{abstract}
Background: Epigenetic regulation is important in hematopoiesis, but the involvement of histone variants is poorly understood. Myelodysplastic syndromes (MDS) are heterogeneous clonal hematopoietic stem cell (HSC) disorders characterized by ineffective hematopoiesis. MacroH2A1.1 is a histone H2A variant that negatively correlates with the self-renewal capacity of embryonic, adult, and cancer stem cells. MacroH2A1.1 is a target of the frequent U2AF1 S34F mutation in MDS. The role of macroH2A1.1 in hematopoiesis is unclear.

Results: MacroH2A1.1 mRNA levels are significantly decreased in patients with low-risk MDS presenting with chromosomal $5 q$ deletion and myeloid cytopenias and tend to be decreased in MDS patients carrying the U2AF1 S34F mutation. Using an innovative mouse allele lacking the macroH2A1.1 alternatively spliced exon, we investigated whether macroH2A1.1 regulates HSC homeostasis and differentiation. The lack of macroH2A1.1 decreased while macroH2A1.1 haploinsufficiency increased HSC frequency upon irradiation. Moreover, bone marrow transplantation experiments showed that both deficiency and haploinsufficiency of macroH2A1.1 resulted in enhanced HSC differentiation along the myeloid lineage. Finally, RNA-sequencing analysis implicated macroH2A1.1-mediated regulation of ribosomal gene expression in HSC homeostasis.
\end{abstract}

Conclusions: Together, our findings suggest a new epigenetic process contributing to hematopoiesis regulation. By combining clinical data with a discrete mutant mouse model and in vitro studies of human and mouse cells, we identify macroH2A1.1 as a key player in the cellular and molecular features of MDS. These data justify the exploration of macroH2A1.1 and associated proteins as therapeutic targets in hematological malignancies.

Keywords: Hematopoiesis, MacroH2A1, Myelodysplastic syndrome

\footnotetext{
* Correspondence: oxana.bereshchenko@unipg.it;

manlio.vinciguerra@fnusa.cz

'Department of Medicine, Department of Philosophy, Social Sciences and

Education, University of Perugia, Perugia, Italy

${ }^{2}$ International Clinical Research Center, St'Anne University Hospital, Brno,

Czech Republic

Full list of author information is available at the end of the article
}

(c) The Author(s). 2019 Open Access This article is distributed under the terms of the Creative Commons Attribution 4.0 International License (http://creativecommons.org/licenses/by/4.0/), which permits unrestricted use, distribution, and reproduction in any medium, provided you give appropriate credit to the original author(s) and the source, provide a link to the Creative Commons license, and indicate if changes were made. The Creative Commons Public Domain Dedication waiver (http://creativecommons.org/publicdomain/zero/1.0/) applies to the data made available in this article, unless otherwise stated. 


\section{Background}

The healthy hematopoietic stem cell (HSC) pool is maintained by genetically and epigenetically regulated gene expression $[1,2]$. When these systems go awry, aberrant hematopoietic stem and progenitor cells may emerge (reviewed in [3]), which are implicated in the development of a heterogeneous group of disorders called myelodysplastic syndromes (MDS). MDS are characterized by ineffective hematopoiesis, leading to variable peripheral blood cytopenias and risk of transformation to acute myeloid leukemia (AML) [4]. MDS can remain stable for many years with few symptoms or can rapidly progress into a more aggressive MDS subtype [5]; current treatment options, however, are limited and often ineffective. Studies have started to identify common mutations underlying HSC dysregulation in MDS, but more progress is needed to identify the molecules and pathways contributing to disease mechanisms.

Recent data have suggested a possible role for histone variants, in particular, the macroH2A1 splice variant macroH2A1.1, in the pathological processes underlying MDS development [6]. Histone macroH2A1 exists as two mutually exclusive exon-spliced isoforms: macroH2A1.1 and macroH2A1.2. These isoforms display largely divergent functions in cell differentiation and tumorigenesis $[7,8]$. MacroH2A1.1 is a potent transcriptional modulator associated with favorable outcomes in several solid tumor types, restriction of cancer stem-cell emergence, and PARP1 (Poly (ADP-ribose) Polymerase-1)-dependent chromatin remodeling [8-20]. The gene encoding human macroH2A1.1 and macroH2A1.2, $H 2 A F Y$, is found on the long arm of chromosome 5 (at $5 \mathrm{q} 31.1$ ), which is deleted in $\sim 20 \%$ of MDS patients. Between 45 and $85 \%$ of MDS patients exhibit mutations in various components of the RNA spliceosome machinery, including U2AF1, ZRSR2, SRSF2, and SF3B1 [21]. Recapitulation of the common U2AF1 S34F mutation in mice reproduces aspects of human MDS and induces dysregulated splicing of multiple gene products, including $H 2 A F Y$ [22]. Yip et al. recently demonstrated that bone marrow $(B M)$ progenitor cells from MDS patients with an endogenous $U 2 A F 1$ S34F mutation showed aberrantly spliced $H 2 A F Y$, resulting in reduced macroH2A1.1, but not macroH2A1.2, isoform expression in both erythroid and granulomonocytic derived colonies [6]. shRNA-mediated silencing of macroH2A1.1 in BM progenitor cells led to increased apoptosis and decreased differentiation when cells were cultured under erythroid and granulomonocytic conditions [6].

Here, we report for the first time that loss of macroH2A1.1 expression in mice led to the dysregulation of myeloid differentiation. RNA-sequencing identified defective production of ribosomal mRNAs as a potential mechanism for disrupted HSC homeostasis following macroH2A1.1 depletion. Thus, macroH2A1.1 delineates its function in HSC homeostasis and differentiation in mice. Moreover, we found that macroH2A1 isoforms' mRNA levels are significantly decreased in MDS patients with a $5 \mathrm{q}$ deletion compared to other MDS groups and healthy individuals.

\section{Results \\ Mice lacking macroH2A1.1 exhibit blood abnormalities under a steady state}

As macroH2A1.1 expression is decreased in U2AF1 S34F MDS patients and its knockdown in vitro perturbs erythroid and granulomonocytic differentiation [6], we sought to investigate macroH2A1.1 function in mice using a gene $\mathrm{KO}$ approach. We first generated a mouse line carrying a conditional macroH2A1 allele that permits selective elimination of one of the two macroH2A protein isoforms using either Cre or Dre recombinase (Fig. 1a).

Mice carrying the targeted (floxed; fl) allele exhibited no phenotype compared to wild-type (WT) mice and were viable and fertile (data not shown). When crossed to deleter HPRT-Cre mice (129S1/Sv-Hprt ${ }^{\text {tm1(CAG-- }}$ cre)Mnn/J) that ubiquitously express Cre in early development [23], the loxP-flanked cassette and exon 6b were removed thereby generating macroH $2 \mathrm{~A} 1.1^{\mathrm{fl} /-}$ mice. These mice were then intercrossed to generate macroH2A1.1 $1^{-/-}$(KO) mice. MacroH2A1. $1^{\mathrm{fl} /-}$ and macroH2A1.1 $1^{-/-}$mice were morphologically and histologically indistinguishable from their WT and macroH2A1. $1^{\mathrm{fl} / \mathrm{fl}}$ littermates under normal conditions, with no overt metabolic, reproductive, or behavioral abnormalities. To confirm the absence of macroH2A1.1 in the $\mathrm{KO}$ cells, we isolated murine embryonic fibroblasts (MEFs) from macroH2A1.1 ${ }^{\mathrm{fl} / \mathrm{fl}}$ and macroH2A1.1 ${ }^{-/-}$ mice, which exhibited comparable cell morphology (Fig. 1b, left panel), and analyzed extracted protein lysates by Western blotting. MacroH2A1.1, but not macroH2A1.2, protein expression was abolished in macroH2A1.1 $1^{-1-}$ KO MEFs (Fig. 1b). We then confirmed undetectable macroH2A1.1 mRNA levels in a panel of tissues isolated from adult (3-month-old) macroH2A1.1 ${ }^{-/-}$ mice, compared to macroH2A1.1 ${ }^{\mathrm{f} / \mathrm{fl}}$ littermates, and reduced macroH2A1.1 mRNA levels by $50 \%$ in macroH2A1. $1^{\mathrm{fl} /}$ heterozygous (HET) mice (Fig. 1c). MacroH2A1.2 transcript abundance was comparable between all macroH2A1.1 genotypes (Fig. 1c). These results confirmed efficient Cre-mediated macroH2A1.1 allele targeting.

Blood counts and biochemical tests identified a low hematocrit and reduced neutrophil counts in macroH2A1.1 ${ }^{\mathrm{fl} /-}$ HET and macroH2A1.1 $1^{-/-}$KO mice compared to macroH2A1.1 ${ }^{\mathrm{fl} / \mathrm{fl}}$ and WT littermates; an opposite trend was observed for lymphocyte and eosinophil cell counts (Additional file 1: Figure S2A and B). No difference in cholesterol or triglyceride levels was observed between groups, but decreased liver transaminase 


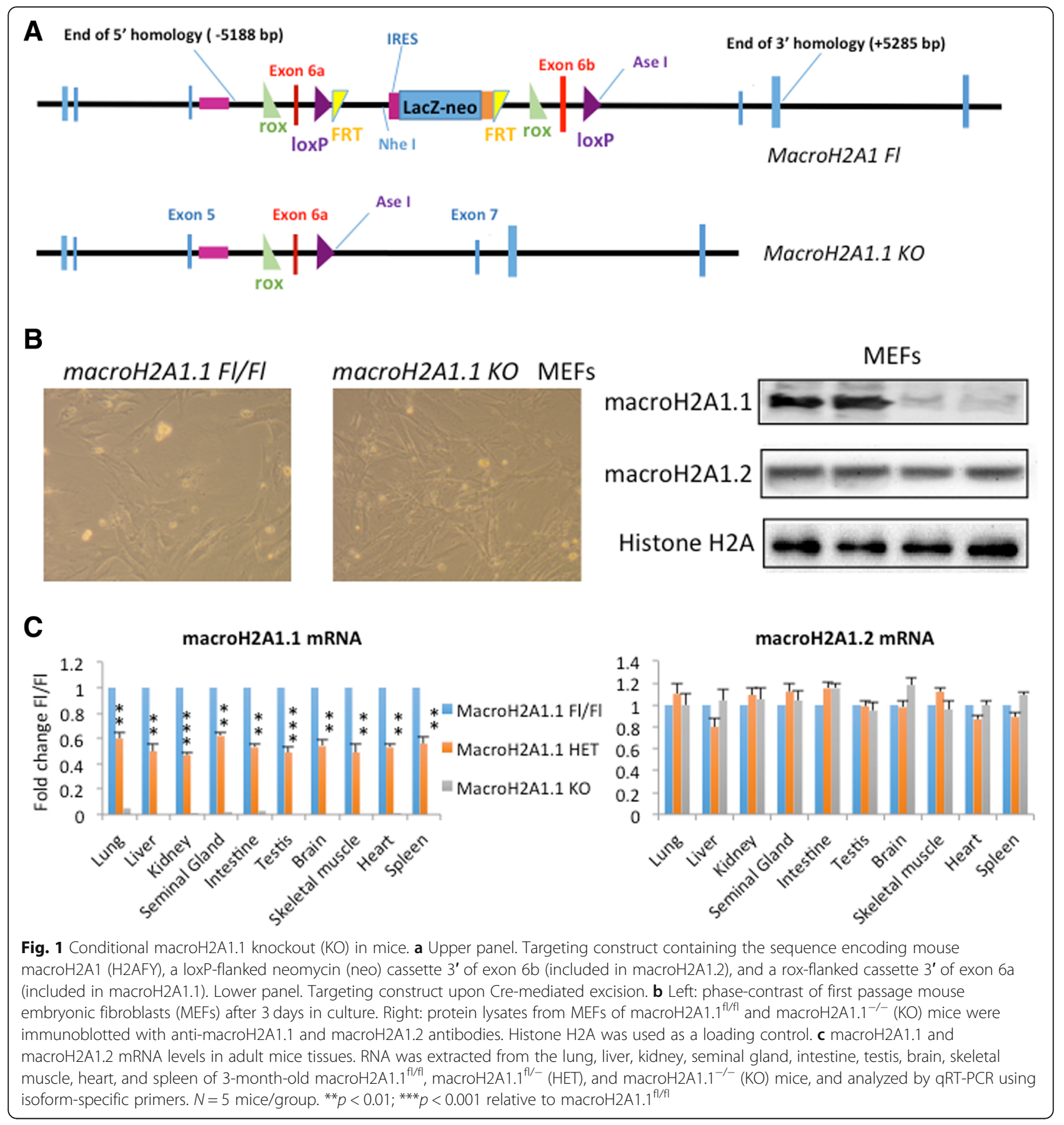

levels were observed in macroH2A1.1 $1^{\mathrm{fl} /-}$ HET and macroH2A $1.1^{-/-} \mathrm{KO}$ mice (Additional file 1: Figure $\mathrm{S} 2 \mathrm{C}$ ). The blood count abnormalities are reminiscent of those observed in human patients with MDS. We also detected lower alanine transaminase (ALT) and aspartate transaminase (AST) levels in macroH2A1. ${ }^{\mathrm{fl} /-}$ $\mathrm{HET}$, and to a greater extent in macroH2A1.1 ${ }^{-1-} \mathrm{KO}$ mice (Additional file 1: Figure S2C), which in humans is associated with higher all-cause mortality $[24,25]$.

\section{MacroH2A1.1 haploinsufficiency or deficiency perturbs hematopoiesis following DNA damage}

An expansion of phenotypically primitive HSCs is often observed in patients with MDS [3]. Murine HSCs are enriched in the bone marrow cell population that do not express mature hematopoietic cell lineage markers $\left(\mathrm{Lin}^{-}\right)$, such as B220, CD4, CD8, Gr-1, Mac-1, and Ter-119, but do express c-Kit and Sca-1, collectively termed LSK ( Lin $^{--}$ Sca- $\left.1^{+} \mathrm{C}-\mathrm{Kit}^{+}\right)$cells [26]. HSC and early progenitors can be 
further characterized within the LSK population based on the surface expression of SLAM (signaling lymphocyte activation molecule) markers CD150 and CD48 [27]. Given the enhanced susceptibility of macroH2A1.1 KO mice to radiation-induced death and cell damage, we tested the effects of haploinsufficiency and absence of the macroH2A1.1 on the hematopoietic compartment at a steady state and under DNA damaging conditions. At a steady state, total bone marrow cellularity (Fig. 2a) as well as the frequency of the LSK CD $48^{-} \mathrm{CD} 150^{+}$HSC did not vary significantly among macroH2A1.1 ${ }^{\mathrm{f} / \mathrm{fl}}$, HET and KO mice (Fig. 2b). Because macroH2A1 isoforms regulate self-renewal and differentiation of induced pluripotent stem cells, embryonic stem cells and cancer stem cells $[11,16,28]$, we hypothesized that
macroH2A1.1 might be involved in regulating the hematopoietic compartment following genotoxic insult in a dose-dependent and time-dependent manner. We analyzed HSCs in the BM of all three macroH2A1.1 genotypes at 1 day (early time point) and 7 days (late time point) after systemic exposure to 600 (low dose) or 1200 rad (high dose) irradiation. Downregulation of c-Kit cell surface expression on functional HSCs has been reported in the situation of distress, such as 5-FU treatment and Myc gene deletion [29]. Since all $\mathrm{Lin}^{-} \mathrm{Sca}-1^{+} \mathrm{CD} 150^{+}$cells in control animals are $\mathrm{c}-\mathrm{Kit}^{+}$, the $\mathrm{Lin}^{-} \mathrm{Sca}-1^{+} \mathrm{CD} 150^{+} \mathrm{CD} 48^{-}$marker combination can also be used to identify HSCs [29]. Since in irradiated mice, we also observed a dramatic reduction in c-Kit ${ }^{+}$cells (data not shown), we used the $\mathrm{Lin}^{-} \mathrm{Sca}-$

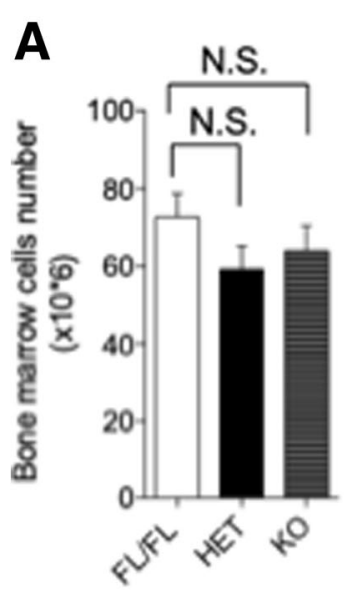

C Low dose IRRAD

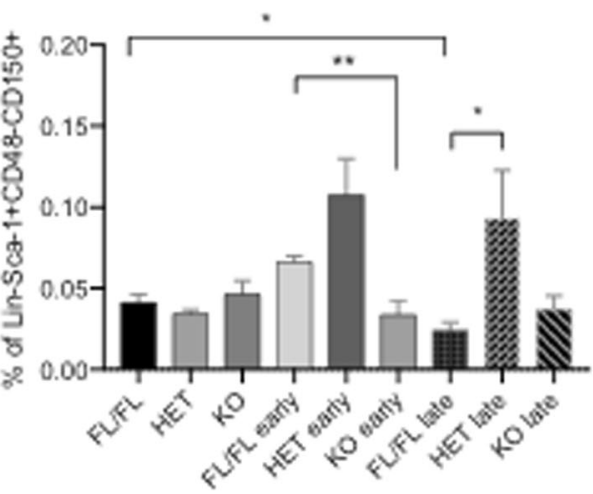

B

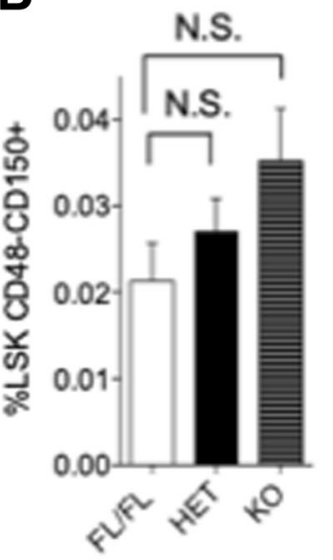

D High dose IRRAD

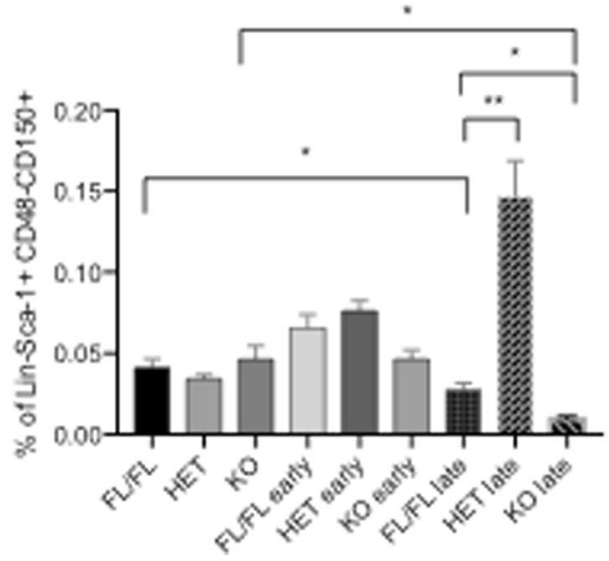

Fig. 2 Assessment of the long-term hematopoietic stem-cell (LT-HSC) pool at a steady state and upon irradiation in macroH2A1. $1^{\mathrm{fl} /-}(\mathrm{HET})$ and macroH2A $1.1^{-1-}(\mathrm{KO})$ mice. Live, Lin ${ }^{-}$cells were gated and analyzed for C-Kit and Sca-1 surface marker expression. Lin ${ }^{-} \mathrm{C}-\mathrm{Kit}^{+} \mathrm{SCa}-1^{+}(\mathrm{LSK}) \mathrm{cells}$

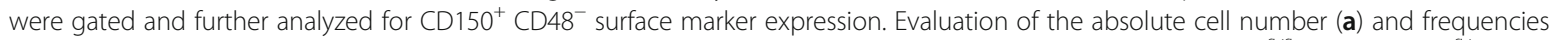
(percentage relative to whole bone marrow cell count) (b) of LT-HSCs in the bone marrow (BM) of macroH2A $1.1^{\mathrm{fl} / \mathrm{fl}}, \mathrm{macroH} 2 \mathrm{~A} 1.1^{\mathrm{fl} /-}(\mathrm{HET})$, and macroH2A1.1 $1^{-1-}(\mathrm{KO})$ mice, at a steady state. $N=5-6$ mice per genotype. $\mathbf{c}$, $\mathbf{d}$ Evaluation of the absolute cell number and frequencies of LT-HSCs

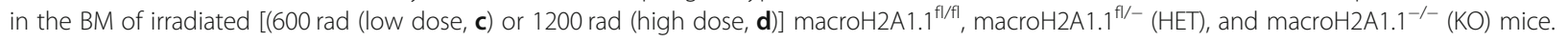
Analyses were performed on days 1 (early time point) or 7 (late time point) after irradiation. Error bars represent the SD. $N=3-4$ mice per genotype. ${ }^{*} p<0.05,{ }^{* *} p<0.01$ relative to macroH2A1. $1^{\mathrm{fl} / \mathrm{fl}}$ 
$1^{+} \mathrm{CD} 150^{+} \mathrm{CD} 48^{-}$marker combination to identify HSC in WT, HET, and KO mice following different doses of irradiation in comparison to the same population in untreated mice. We observed that the macroH2A1.1 haploinsufficiency caused a significant increase in HSC frequency at late time point following low-dose (Fig. 2c) and high-dose (Fig. 2d) irradiation compared to WT mice. Conversely, the macroH2A1.1 $1^{-/}$mice showed a decrease in HSC frequency, caused by low (Fig. 2c, early time point) and high (Fig. 2d) doses of irradiation, compared to untreated and similarly treated WT mice. Altogether, these data demonstrate that the macroH2A1.1 isoform regulates HSC response to irradiation in a time- and dosedependent manner.

\section{MacroH2A1.1 haploinsufficiency or deficiency in HSCs leads to a myeloid differentiation bias in transplantation assays}

A myeloid differentiation bias is found in human patients with MDS [3]. To understand the downstream effects of macroH2A1.1 haploinsufficiency or deficiency on $\mathrm{HSC} /$ hematopoietic progenitor cells (HPC) populations, we analyzed the BM from macroH2A1.1 $1^{\mathrm{f} / \mathrm{ll}}$, macroH2A1. $1^{\mathrm{fl} /}$ $\mathrm{HET}$, and macroH2A1.1 ${ }^{-/-} \mathrm{KO}$ mice by flow cytometry. Higher frequencies of myeloid $\left(\mathrm{Mac}-1^{+}\right)$cells were found in macroH2A1.1 $1^{-/-}$KO mice compared to macroH2A1. $1^{\mathrm{f} / \mathrm{fl}}$ mice, and lower frequencies of $\mathrm{B}\left(\mathrm{B} 220^{+}\right)$cells were found in both macroH2A1.1 $1^{\mathrm{fl} /-}$ HET and in macroH2A1.1 $1^{\mathrm{f} / \mathrm{fl}}$ mice (Fig. 3a). To demonstrate that the cause of this myeloid bias observed in macroH2A1.1 $1^{-/-} \mathrm{KO}$ mice is intrinsic to the hematopoietic system, we performed an in vivo transplantation study. Here, flow cytometry analysis confirmed higher frequencies of myeloid cells and lower frequencies of $\mathrm{B}$ cells in the peripheral blood of mice receiving macroH2A1. $1^{\mathrm{fl} /}$ HET or macroH2A1.1 $1^{-/-}$KO BM cells, compared to mice receiving macroH2A1. $1^{\mathrm{f} / \mathrm{fl}} \mathrm{BM}$ cells (Fig. $3 \mathrm{~b}-\mathrm{d}$ ). The myeloid differentiation bias was also observed in HET mice in noncompetitive BM transplantation assay (Fig. 3c). Moreover, the analysis of the frequencies of myeloid progenitor sub-populations revealed a tendency increase in GMPs (Lin/IL7R/Sca- $1^{-}$c-Kit ${ }^{+} \mathrm{CD} 34^{+} \mathrm{CD} 16 / 32^{+}$) and a tendency decrease in megakaryocyte-erythrocyte progenitors (MEPs; $\mathrm{Lin}^{-} / \mathrm{IL} 7 \mathrm{R} / \mathrm{Sca}-1^{-} \mathrm{c}-\mathrm{Kit}^{+} \mathrm{CD} 34^{-} \mathrm{CD} 16 / 32^{-}$) in the $\mathrm{BM}$ of macroH2A1.1 $1^{\mathrm{fl} /-}$ HET and macroH2A1.1 $1^{-/-}$KO mice compared to macroH2A1. $1^{\mathrm{f} / \mathrm{fl}}$ mice (Fig. 3e). These data show that decreased macroH2A1.1 levels has a profound impact on HSC differentiation in the BM, resulting in a myeloid skewing similar to that observed in human MDS.

\section{Downregulation of ribosomal protein genes after macroH2A1.1 depletion}

To gain a mechanistic insight into the hematopoietic derangements associated with decreased macroH2A1.1 expression, we performed transcriptome-wide RNA sequencing
(RNA-Seq) to identify differentially expressed genes (DEGs) between HPCs (CD150-CD48 $\left.{ }^{+} \mathrm{LSK}\right)$ isolated by cell sorting from macroH2A1.1 $1^{-1-} \mathrm{KO}$ and macroH2A1.1 $1^{\mathrm{f} / \mathrm{fl}}$ mice. Using a 1.5-fold change threshold, we identified 599 DEGs, of which 225 were upregulated and 374 were downregulated in macroH2A1.1 $1^{-/-}$compared to macroH2A1.1 ${ }^{\mathrm{f} / \mathrm{fl}}$ controls (Additional file 2: Table S1). KEGG analysis revealed that these genes significantly over-represented the ribosome pathway, protein processing in the endoplasmic reticulum, and the cysteine/methionine metabolism pathways (Fig. 4a). The ribosome pathway was the most significantly enriched pathway in our experiment (Fig. 4b), with 16 differentially expressed ribosomal proteins with their functional location within the large (Rpl) and small (Rps) subunits. Furthermore, we found the broad functions of chromatin modification/remodeling, transcription, redox cell metabolism, cytoskeleton homeostasis, and cellular response to DNA damage stimulus among the top 20 most represented biological processes (Gene Ontology, GO) in macroH2A1.1 $1^{-1-}$ HPCs (Fig. 4c). As defective ribosome biogenesis has been reported in MDS [30], we next asked whether macroH2A1.1-deficiency-driven changes in ribosomal protein gene expression underpin pathology in hematopoietic cells. We stably knocked down (KD) macroH2A1.1 mRNA in human promyelocytic leukemia HL-60 and monocytic THP-1 cell lines grown in suspension [31], using lentivirally transduced shRNAs against the $H 2 A F Y$ gene. Upon efficient specific silencing of the macroH2A1.1 transcript (without altering the levels of macroH2A1.2 isoform) (Additional file 1: Figure S3A, B), we measured transcript levels for a subset of $\operatorname{Rpl}(19,29,38)$ and Rps $(15 \mathrm{a}, 21)$ genes, whose expression displayed $>$ twofold change in our RNA-Seq analysis (Additional file 2: Table S1). MacroH2A1.1 KD led to decreased Rpl19 (fivefold), Rpl29 (twofold), Rpl38 (fivefold), Rps15a (sixfold), and Rps21 (twofold) mRNA levels in both HL-60 and THP-1 cells (Additional file 1: Figure S3C, D), consistent with our RNA-Seq findings made in macroH2A1.1 ${ }^{-1-}$ mouse HPCs (Fig. 4). In order to obtain evidence that macroH2A1.1 deficiency-dependent decreased ribosomal protein gene expression may lead to defective ribosome biogenesis and protein synthesis, we assessed the steady-state $47 \mathrm{~S}$ prerRNA level in macroH2A1.1 $1^{-/-}$HPCs, and in human HL60 and THP-1 cells KD for macroH2A1.1. Under these conditions, a $\sim 85 \%$ decrease in the relative amount of $47 \mathrm{~S}$ pre-rRNA was observed in macroH2A1.1 $1^{-1-}$ HPCs compared to macroH2A1. $1^{\mathrm{f} / \mathrm{l}}$ HPCs (Fig. 5a). Similarly, a $\sim 70 \%$ and $\sim 60 \%$ decrease in the relative amount of $47 \mathrm{~S}$ pre-rRNA was observed in HL-1 and in THP-1 cells, respectively (Fig. 5b). In addition, we performed a protein synthesis inhibition assay using puromycin, an antibiotic that competes by acting as an analog of the three-terminal end of aminoacyl-tRNA, disrupting protein synthesis. To this purpose, we performed a $[3 \mathrm{H}]$-leucine incorporation 

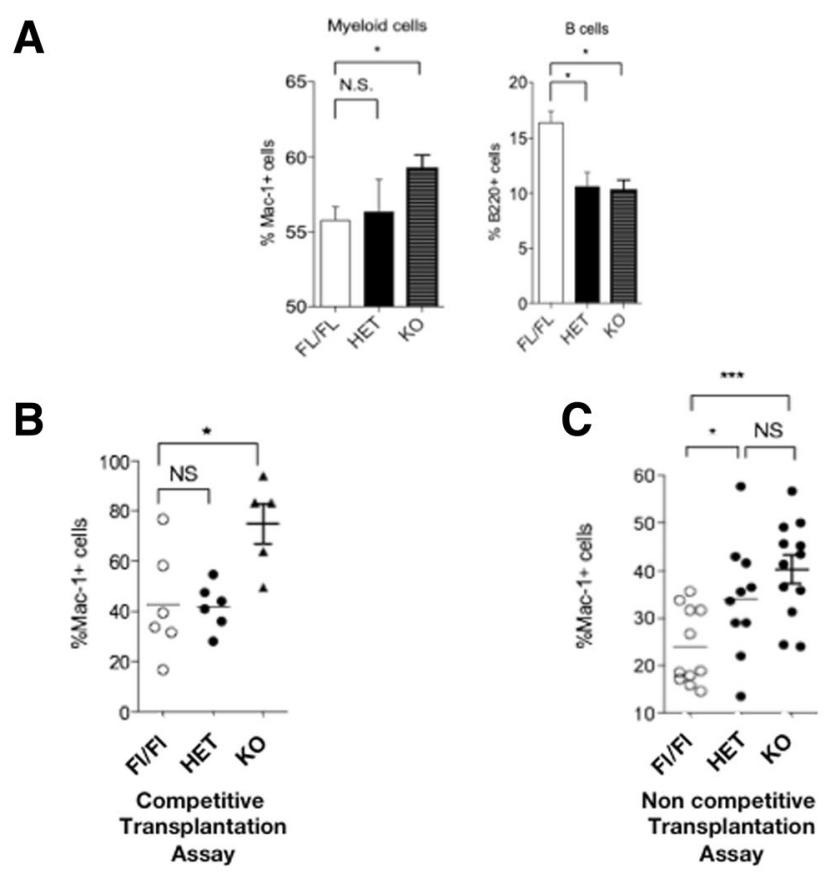

D
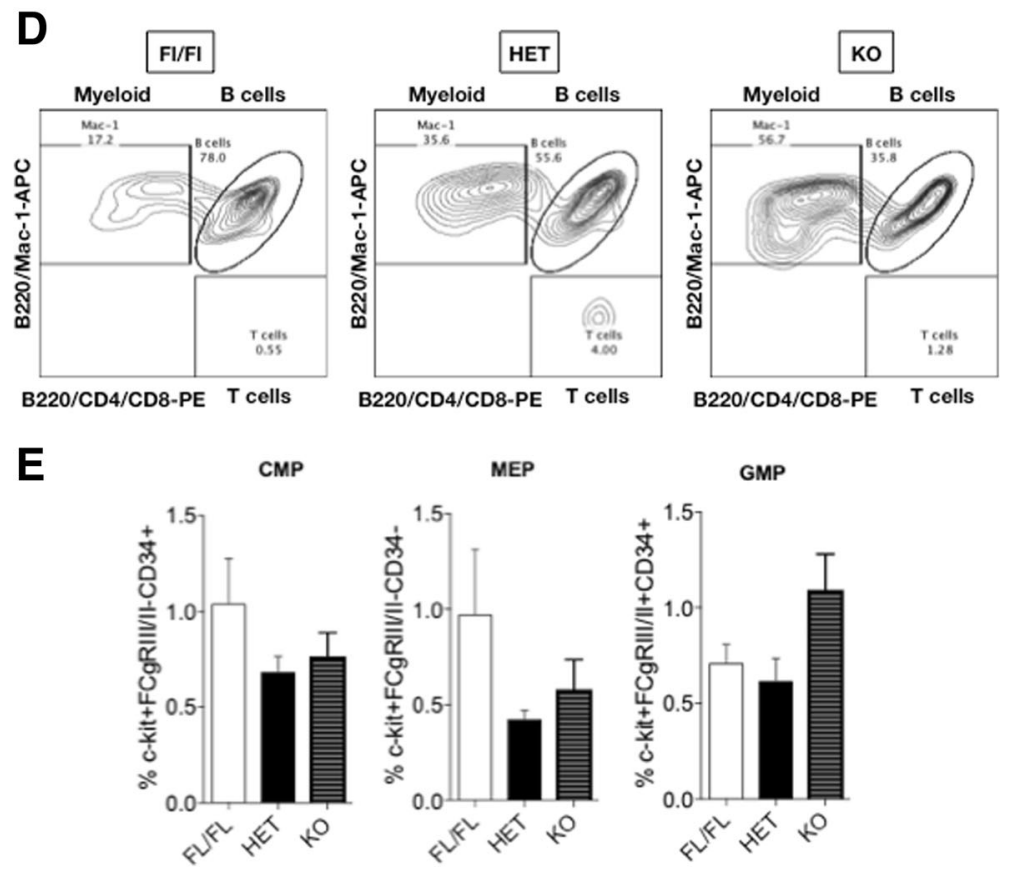

Fig. 3 MacroH2A1.1 deficiency causes myeloid bias upon bone marrow (BM) transplantation. a Peripheral blood (PB) analysis from

macroH2A $1.1^{\mathrm{fl} / \mathrm{fl}}$, macroH2A $1.1^{\mathrm{fl} /-}(\mathrm{HET})$, and macroH2A $1.1^{-1-}(\mathrm{KO})$ mice showing the percentage of myeloid-cell $\left(\mathrm{Mac}-1^{+}\right)$and $\mathrm{B}-\mathrm{cell}\left(\mathrm{B} 22 \mathrm{O}^{+}\right)$gated populations. b, $\mathbf{c}$ Dot plots of PB analysis from animals transplanted with macroH2A1. $1^{\mathrm{fl} / \mathrm{fl}}$, macroH2A1. $1^{\mathrm{fl} /-}(\mathrm{HET})$, and macroH2A1.1 ${ }^{-/-}(\mathrm{KO}) \mathrm{BM}$ cells in a competitive (b) or noncompetitive (c) transplantation assay. Both plots show the percentage of myeloid cells $\left(\right.$ Mac- $1^{+}$) within engrafted CD $45.2^{+}$cells. $\mathbf{d}$ Representative plots indicating in each quadrant the frequency of gated cell populations within CD45.2 $2^{+}$cells. Graphs show the frequency of $\left[\mathrm{Mac}^{-} 1^{+}, \mathrm{B}\left(\mathrm{B} 22 \mathrm{O}^{+}\right)\right.$, and $\mathrm{T}\left(\mathrm{CD}^{+} / \mathrm{CD}^{+}\right)$cells] within $\mathrm{CD} 45.2^{+}$cells. e Frequencies of CMPs, MEPs, and GMPs in the BM of irradiated macroH2A1. $1^{\mathrm{fl} / \mathrm{fl}}$, macroH2A1.1 $1^{\mathrm{fl} /-}(\mathrm{HET})$, and macroH2A1.1 $1^{-1-}(\mathrm{KO})$ mice. Graphs represent CMP (Lin $\left.{ }^{-} \mathrm{C}-\mathrm{Kit}^{+} \mathrm{SCa}-1^{-} \mathrm{CD} 34^{+} \mathrm{CD} 16 / 32\right), \mathrm{MEP}\left(\mathrm{Lin}^{-} \mathrm{C}^{-}\right.$ $\left.\mathrm{Kit}^{+} \mathrm{Sca}-1^{-} \mathrm{CD} 34^{-} \mathrm{CD} 16 / 32^{-}\right)$, and GMP $\left(\mathrm{Lin}^{-} \mathrm{C}-\mathrm{Kit}^{+} \mathrm{SCa}-1^{-} \mathrm{CD} 34^{+} \mathrm{CD} 16 / 32^{+}\right)$frequencies in the BM. Results are presented as the means $\pm \mathrm{SEM}$ of three independent experiments. $N=6-10 /$ group. ${ }^{*} p<0.05,{ }^{* *} p<0.001$, NS $=$ not significant 


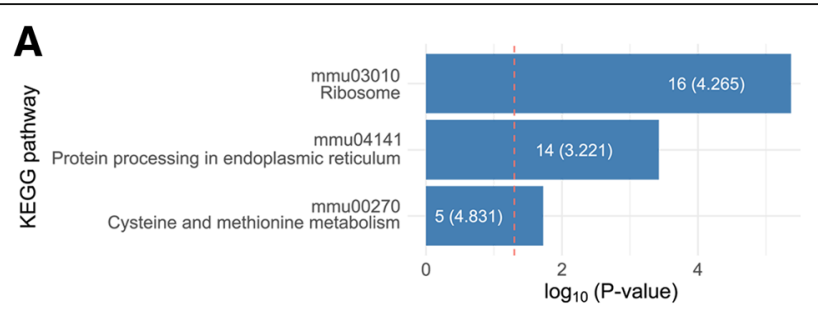

B

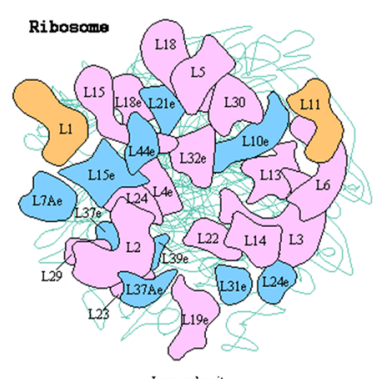

Ribosomal RNAs
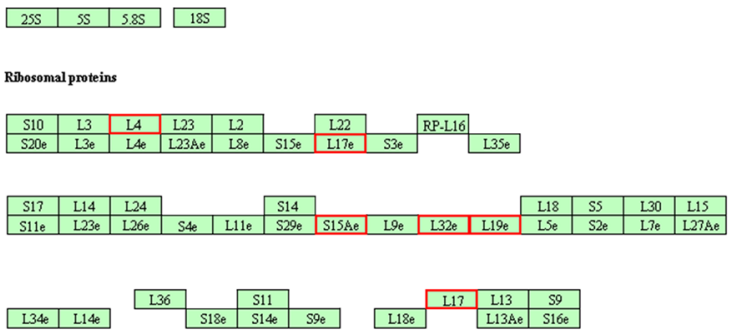

Large suburu
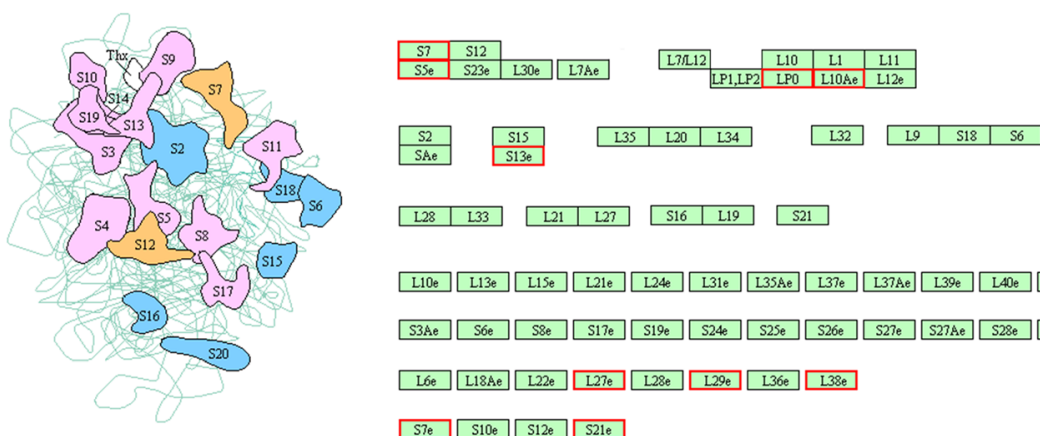

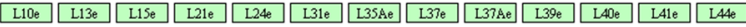

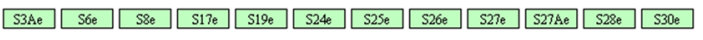

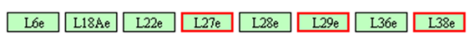

Small subunit

\begin{tabular}{|lll}
\hline S3e & S10e & S12e \\
\hline
\end{tabular}
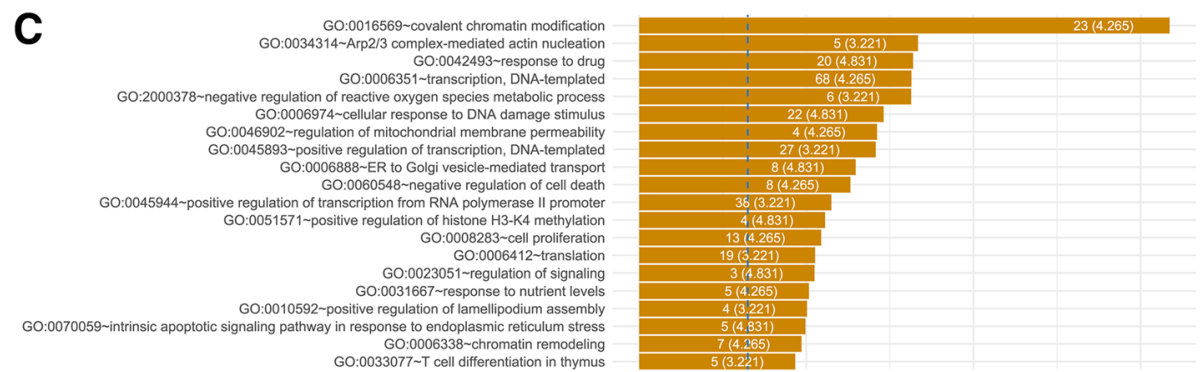

Fig. 4 RNA-Seq and bio-informatic analyses on multipotent progenitor cells (CD150-CD48 $\left.{ }^{+} \mathrm{LSK}\right)$ isolated from bone marrow and using flow cytometry. a KEGG pathways significantly represented by the differentially expressed genes. Enrichment-log ( $p$ values) is reported on the $x$-axis. The dashed red line marks the significant enrichment threshold ( $p$ value =0.05). b Mouse KEGG map (mmu03010) of the Ribosome pathway. $\mathbf{c}$ Top 20 most enriched Gene Ontology biological processes. The blue line marks the significance enrichment threshold $(p$ value $=0.05)$, and text within a bar refers to the number of significantly expressed genes belonging to a process and the overall enrichment score (into brackets)

assay upon treatment with puromycin $(0,0.5,2 \mu \mathrm{g} / \mathrm{ml})$ for $72 \mathrm{~h}$ in HL-60 and THP-1 cells; our findings show that protein synthesis was significantly inhibited in HL-1 and THP1 cells even in the absence of puromycin, and it was further inhibited upon treatment with $0.5 \mu \mathrm{g} / \mathrm{ml}$ puromycin (Fig. 5c). Two micrograms per milliliter puromycin was lethal in both cell lines (Fig. 5c).

In fact, macroH2A1.1 KD was associated with a $\sim 60$ $80 \%$ decrease in cell viability of both HL-60 and THP-1 cells (Fig. 6a, b). This decrease was due to increased apoptosis, as a 48-h pre-incubation of the cells with the pan-caspase inhibitor Z-VAD-FMK (carbobenzoxy-valylalanyl-aspartyl-[O-methyl]-fluoromethylketone; $\quad 10 \mu \mathrm{M}$ ) completely rescued viability (Fig. 6a, b). Conversely, stable lentivirus-mediated overexpression of macroH2A1.1 fused to GFP(9) in HL-60 cells (Fig. 7a) led to increased cell proliferation (Fig. 7b). Treating HL-60 cells with phorbol 12myristate 13-acetate (PMA) drives their differentiation 


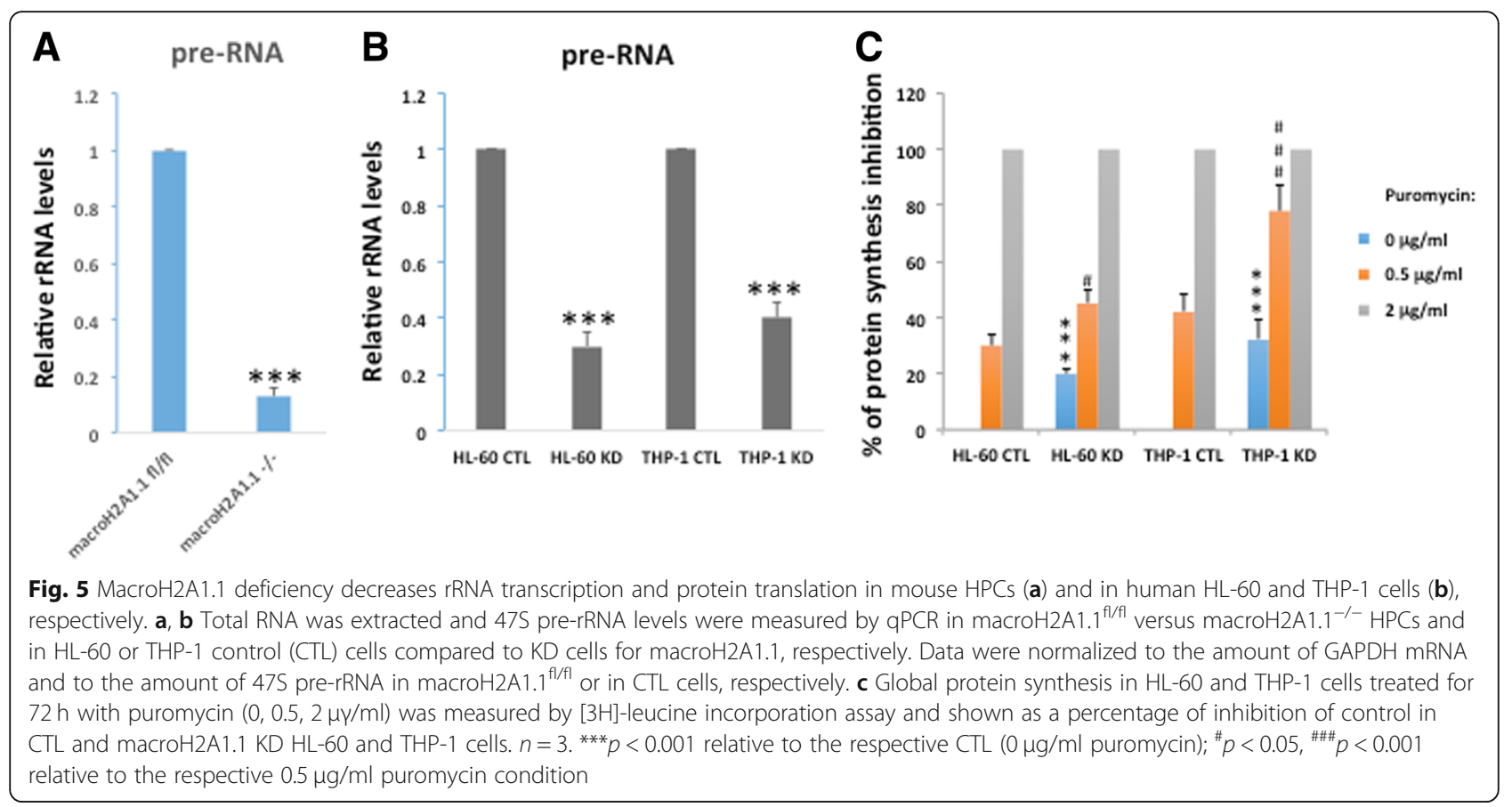

toward a monocytic lineage [32]; however, here, we found that this process was apparently unaffected by macroH2A1.1 overexpression, with over-expressing cells successfully upregulating $\mathrm{CD} 11 \mathrm{~b}$ expression (Fig. $7 \mathrm{c}$ ) and becoming adherent (Fig. 7d, e). PMA-driven differentiation was also unaffected by KD of macroH2A1.1 in the population of cells that remained viable (Fig. 7e).

\section{MacroH2A1 isoforms' transcript levels are decreased in the BM of MDS patients carrying a 5q deletion or U2AF1 S34F mutation}

We first compared the BM expression levels of macroH2A1.1 or macroH2A1.2 between sub-groups of MDS patients with different genetic abnormalities and healthy controls $(n=5)$. MDS patients $(n=24$ total $)$ were categorized as either having a normal karyotype $(\mathrm{NK} ; n=4)$; a $5 \mathrm{q}$ deletion $(\operatorname{del}(5 \mathrm{q}) ; n=15)$, of which seven also additional cytogenetic changes; or a nondel5q abnormal karyotype (AK; $n=5$ ) (Additional file 3: Table S2). As expected, del(5q) patients expressed significantly lower macroH2A1.1 and macroH2A1.2 mRNA levels compared to healthy controls $(p<0.05)$, due to the loss of $H 2 A F Y$ located at $5 \mathrm{q} 31.1$ within the commonly-deleted $5 \mathrm{q}$ region (Fig. 8a, b). By contrast, NK and AK MDS patients showed normal macroH2A1.1/macroH2A1.2 mRNA levels (Fig. 8a, b). Aberrant $H 2 A F Y$ splicing causing specifically reduced macroH2A1.1, but not macroH2A1.2, expression has been associated with the U2AF1 S34F mutation in MDS [6]. However, only three MDS patients in this cohort carried this mutation, and they were not $\operatorname{del}(5 \mathrm{q})$ carriers
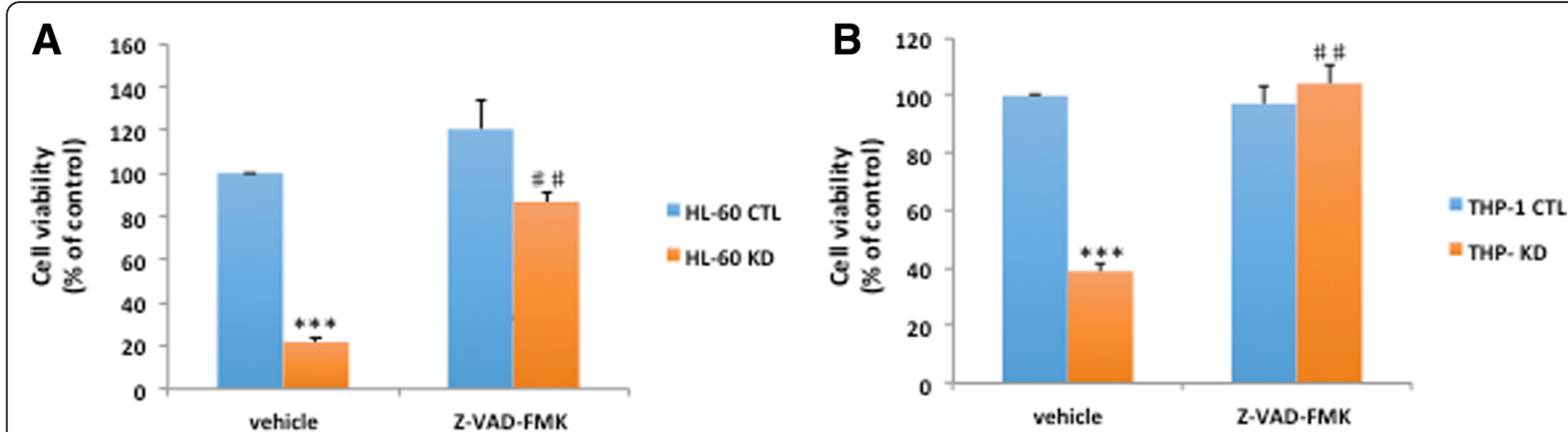

Fig. 6 a, b MacroH2A1.1 knockdown (KD) affects cell viability in HL-60 and THP-1 cells. a, b Cell viability assay in HL-60 (a) and THP-1 (b) cells, incubated or not for $48 \mathrm{~h}$ in the presence of $10 \mu \mathrm{M}$ pan caspase inhibitor Z-VAD-FMK. Data are presented as means relative to CTL cells, $+/-$ SD, $n=4 .{ }^{* *} p<0.001$ relative to $\mathrm{CTL}$ 


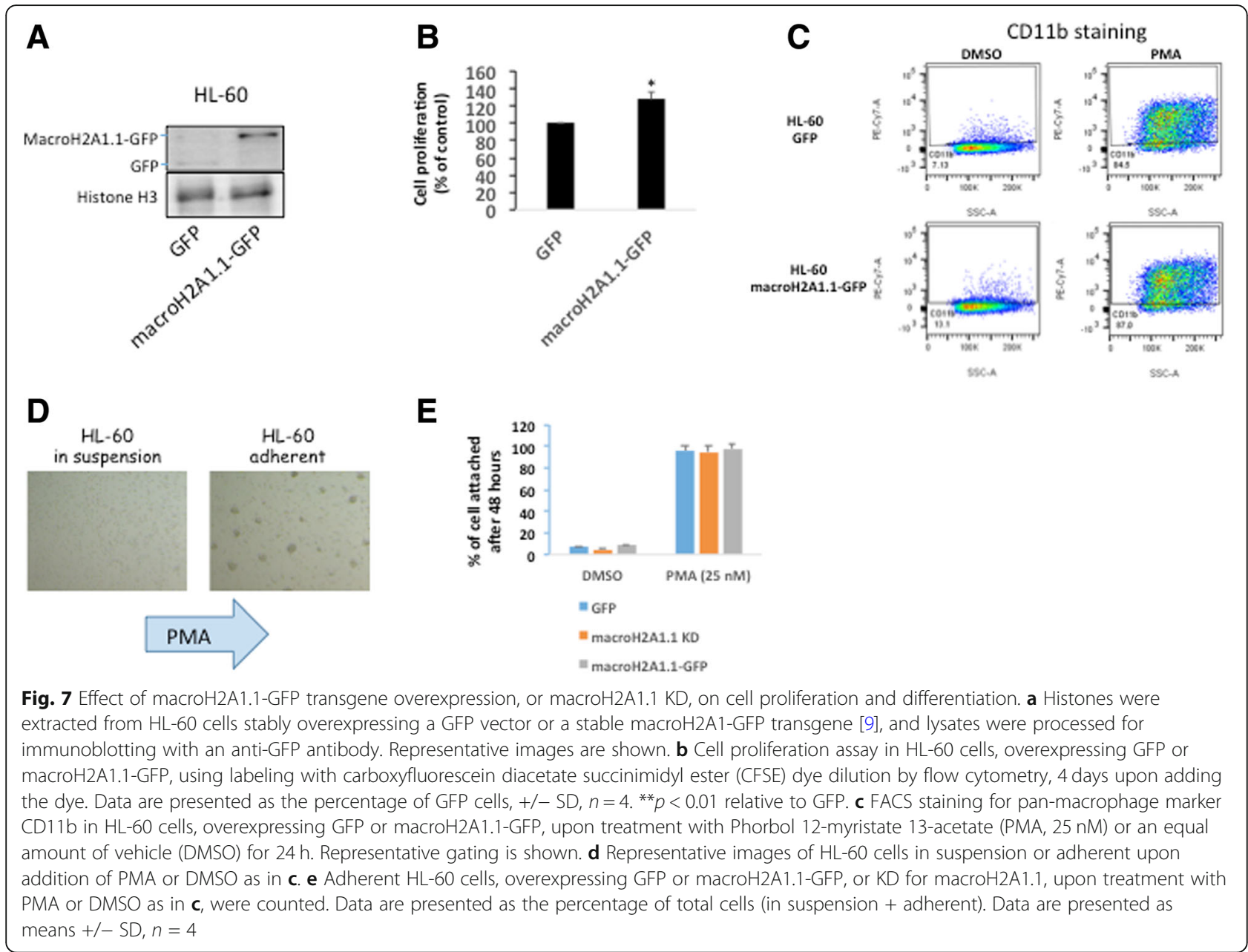

(Additional file 3: Table S2). When comparing these U2AF1 mutants versus healthy subjects, we detected a decreased, albeit not significant, macroH2A1.1 but not macroH2A1.2 mRNA expression (Fig. 8c, d), according to previous studies [6]. These data provide evidence that macroH2A1.1 mRNA tends to decrease in the BM of MDS patients carrying the $U 2 A F 1 S 34 F$ mutation and that both macroH2A1.1 isoforms' transcript levels are decreased in the BM of MDS patients who are $\operatorname{del}(5 \mathrm{q})$ carriers.

\section{Conclusions}

Here, we show that the histone variant macroH2A1.1, which is downregulated in a subset of patients with MDS, profoundly affects the survival and differentiation of murine HSCs/HPCs in vivo and human leukemic cell lines in vitro. We provide evidence that macroH2A1.1 is required for normal ribosomal protein gene expression in HPCs. Without proper expression of this histone variant, abundant cell death occurred in the hematopoietic cells. Uncovering the relationship between macroH2A1.1 depletion and defective ribosomal biogenesis in HSCs/
HPCs provides a critical link between this epigenetic regulator and the molecular pathologies typical of MDS.

Our findings are in line with a recent report from Yip et al. [6]. These authors analyzed the role of the mutation S34F in the splicing factor U2AF1, which is frequent in MDS: U2AF1 S34F altered mRNA splicing of many transcripts and among those $H 2 A F Y$ (coding for macroH2A1.1 and macroH2A1.2). Only 3 out of 29 patients in our cohort displayed U2AF1 S34F mutation; in those individuals, we observed a not statistically significant tendency toward a decrease in macroH2A1.1, but not macroH2A1.2 mRNA level: analyses on larger cohorts are required to corroborate these data [6].

$H 2 A F Y$ is physically localized on the long arm of chromosome 5, implying a connection with the most common karyotypic abnormality in MDS-del(5q). As expected, both macroH2A1.1 and macroH2A1.2 mRNA levels were found decreased in the BM of $\operatorname{del}(5 \mathrm{q})$ MDS patients, compared to healthy subjects.

MacroH2A1.1 but not macroH2A1.2, which is deficient in poly-ADP-ribose binding, is required for PARP-1 activation $[16,28,33,34]$. MacroH2A1 and PARP1 activities have been 


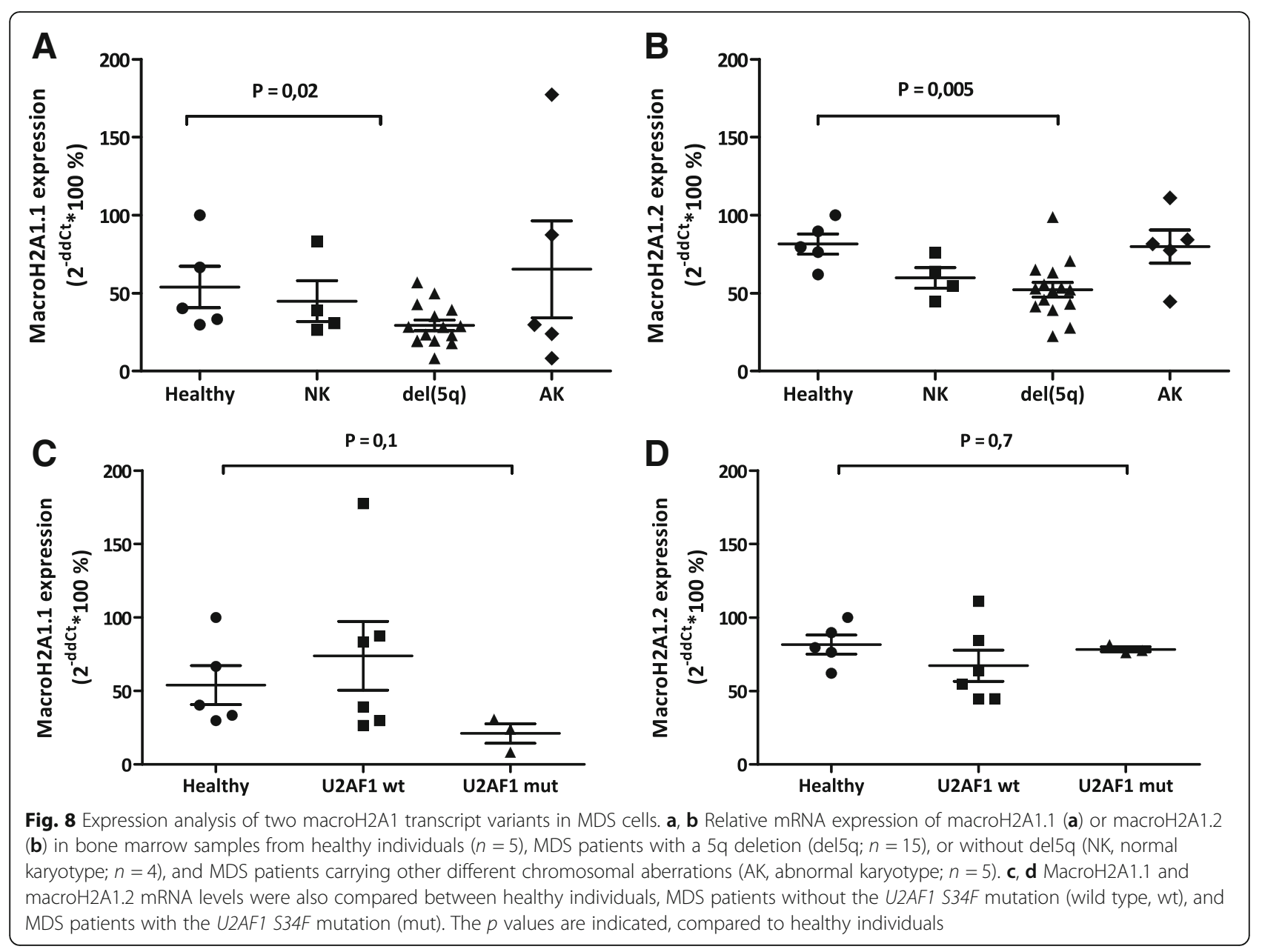

independently implicated in ribosome assembly [35-37]. Mutational [38] and transcriptomic [39] approaches have not fully clarified yet the role of del(5q) in MDS pathogenesis; however, CSNK1A1 [40] and RPS14 [41] have been identified as strong promising therapeutic targets. Hematopoietic differences observed in macroH2A1.1 haploinsufficient and macroH2A1.1-deleted mice have been similarly reported in a murine model displaying conditional inactivation of CSNK1A1 [40]. In this model, CSNK1A1 haploinsufficiency induced HSC expansion, whereas homozygous deletion caused HSC failure [40]. If CSNK1A1 and macroH2A1.1 functionally interact in regulating, hematopoiesis remains to be established. The phenotype of our newly generated macroH2A1.1 haploinsufficient mouse recapitulates several features of human MDS, including anemia, neutropenia, expansion of the LT-HSC pool, and a marked level of susceptibility to irradiation and defective myelopoiesis [3].

Various transcriptional and epigenetic mechanisms contribute to HSC maintenance and stepwise differentiation to produce distinct hematopoietic lineages [42, 43], and macroH2A1.1 has only recently emerged as a novel epigenetic regulator of hematopoiesis. Silencing macroH2A1.1 expression in human progenitor cells alters erythroid and granulomonocytic differentiation, and the reintroduction of macroH2A1.1 in U2AF1 mutant BM cells rescues cell death and their differentiation potential [6]. Consistently, we found that in lineage-committed HL-60 (neutrophils) and THP-1 (monocytes) human myelomonocytic leukemia cell lines, KD for macroH2A1.1 led to massive reduction in proliferation and death, and that macroH2A1.1 haploinsufficiency, and to a lesser extent, its full deficiency, tends to decrease the frequency of CMPs and MEPs, and to increase GMPs in mice. Expanded GMPs characterize high-risk MDS [44]. Compared to in vitro shRNA-mediated silencing or full in vivo $\mathrm{KO}$, we believe that the features of our newly generated macroH2A1.1 haploinsufficient mouse might be more akin to the pathological changes observed in MDS patients. In fact, we also detected a myeloid bias in mice that lack the full dose of macroH2A1.1: the hematopoietic cell-autonomous enrichment of myeloid Mac-1+ cells parallels the myeloid differentiation bias that is commonly observed in other MDS murine models and in human MDS. MDS is characterized 
on one hand by dysplastic myeloid expansion, with myeloid cells that have reduced ability to differentiate, and on the other hand by neutropenia, thrombocytopenia, and anemia [45-47]: we propose macroH2A1.1 ${ }^{-/-}$mouse as a useful tool for further mechanistic studies on MDS.

By characterizing the phenotype of macroH2A1.1-insufficient mice, we report also another primary in vivo role for macroH2A1.1 in hematopoiesis: our RNA-Seq analysis of HPCs from macroH2A1. $11^{-/-}$mice identified a substantial depletion of many transcripts [small ribosomal proteins (Rps) and large ribosomal proteins $(\mathrm{Rpl})]$ involved in ribosome assembly, and this was confirmed in HL-60 and THP-1 myeloid cell lines. Moreover, we found that macroH2A1.1 $1^{-/}$HPCs and HL-60/THP-1 KD for macroH2A1.1 display decreased levels of $47 \mathrm{~S}$ pre-rRNA, a long primary transcript that is the precursor of three of the four ribosomal RNAs: $18 \mathrm{~S}, 5.8 \mathrm{~S}$, and $28 \mathrm{~S}$. Within ribosome structure, the $18 \mathrm{~S}$ rRNA assembles with $33 \mathrm{Rps}$ to form the $40 \mathrm{~S}$ ribosomal subunit or small subunit, while the $5 \mathrm{~S}, 5.8 \mathrm{~S}$, and $28 \mathrm{~S}$ rRNAs associate with $47 \mathrm{Rpl}$ to assemble the $60 \mathrm{~S}$ or large subunit. $47 \mathrm{~S}$ pre-rRNA and Rps/ Rpl levels might thus be connected events leading to defective ribosome biogenesis in macroH2A1.1 ${ }^{-/-}$HPCs. Although the causal role for ribosomal biogenesis in HSC maintenance is not fully understood, impaired ribosome biogenesis-induced nuclear stress, for instance, due to hemizygosity for genes encoding ribosomal proteins, is associated with the development of clinical entities collectively known as "ribosomopathies" which include several bone marrow failure syndromes, including MDS [48]. We speculate that macroH2A1.1 depletion in the hematopoietic system might have two deleterious effects. First, it alters HSC homeostasis through defective ribosomal production [30]: adult HSCs display low levels of global protein synthesis relative to HPCs and genetic perturbations that alter the dynamics of protein synthesis impair HSC function [49]. Our data suggesting that macroH2A1.1-dependent impairment in ribosome biogenesis relates to impaired HSC differentiation are consistent with Signer et al., who demonstrated that reduced ribosome function in $\mathrm{Rp} 24$ mice reduced protein synthesis of 30\% in HSCs and impaired HSC function [50].

Second, given the extensive Rpl and Rps expression heterogeneity in the hematopoietic system [51], macroH2A1.1 $1^{-/-}$might disrupt the regulation of hematopoietic lineage-specific ribosomal proteins that might be involved in lineage differentiation. Predicting the phenotypes of perturbed Rpl and Rps expression patterns remains challenging and is an area that warrants future research.

In summary, our study shows that a loss of macroH2A1.1, which affects a subset of MDS patients, has a critical role in the defective hematopoiesis and perturbed ribosomal biogenesis that are central to MDS pathology.
By combining clinical data with a discrete mutant mouse model and in vitro studies of human cells, we identify macroH2A1.1 as a key determinant of the cellular and molecular features of MDS. These data justify the exploration of macroH2A1.1 and associated proteins as therapeutic targets in hematological malignancies.

\section{Methods}

\section{Clinical and laboratory data of MDS patients}

Bone marrow aspirates, clinical information, and routine laboratory data were collected from 24 patients diagnosed with MDS according to the revised World Health Organization criteria [52] and prior to commencement of treatment, at the University Hospital Brno. Basic MDS patients and cytogenetic characteristics are shown in Additional file 3: Table S2. U2AF1 mutation analyses were performed as described previously [6].

Human bone marrow cell isolation and sample processing Red blood cells were depleted using ACK lysing buffer $\left(\mathrm{NH}_{4} \mathrm{Cl} 150 \mathrm{mM}, \mathrm{KHCO}_{3}, 10 \mathrm{mM}, \mathrm{Na}_{2}\right.$ EDTA $0.1 \mathrm{mM}$, $\mathrm{pH}$ 7.2). White blood cells were further processed for RNA isolation. Total RNA was isolated using TriReagent (MRC, USA) according to the manufacturer's instructions and the quality of RNA was assayed with an Agilent 2100 Bioanalyser (RNA 6000 Nano Assay; Agilent Technologies, USA).

\section{Animal models}

Mice lacking macroH2A1.1 were generated as follows: a $12 \mathrm{~kb}$ segment of the murine H2AFY gene (introns 5-8) was subcloned from a BAC by recombineering into p15A-HSV tk-DTA-amp. A lacZ-neo cassette [53], flanked by loxP and rox sites at the $5^{\prime}$ and $3^{\prime}$ ends, respectively, was inserted into the intron between exons $6 \mathrm{a}$ and $6 \mathrm{~b}$, also by recombineering [54]. Another rox site was inserted upstream of exon 6a and another loxP site inserted downstream of exon 6b so that Dre/rox recombination [55] would remove exon 6a and the lacZ-neo cassette, and Cre/loxP recombination would remove exon $6 \mathrm{~b}$ and the lacZ-neo cassette; thus, Cre recombination will eliminate macroH2A1.1 expression. Southern blotting of genomic NheI-digested DNA from individual ES-cell-derived clones with a $3^{\prime}$ probe was used to identify homologous recombinants (Additional file 1: Figure S1). A 12.3-kb DNA fragment corresponds to the wild-type macroH2A1.1 locus; integration of the loxP-flanked neomycin cassette $3^{\prime}$ of exon $6 \mathrm{~b}$ introduced an additional NheI site, thus increasing the size of the NheI DNA fragment to $16.2 \mathrm{~kb}$ in the targeted allele (Additional file 1: Figure S1). Cre-mediated recombination resulted in a 3.9$\mathrm{kb}$ NheI DNA fragment recognized by the 3 ' probe, which is diagnostic of the macroH2A1.1 allele. The targeting of the macroH2A1.1 allele was performed by electroporation 
of A9 ES cells, which were then injected into C57BL/6 eight cell-stage embryos. The targeted macroH2A $1^{\mathrm{fl} / \mathrm{fl}}$ mice were crossed to deleter HPRT-Cre mice (129S1/Sv-

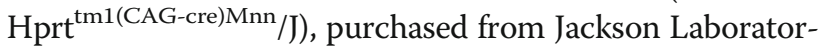
ies, USA, to remove the loxP-flanked neomycin cassette and generate macroH2A $1.1^{\mathrm{fl} /}$ mice (heterozygous, HET), respectively. Mice heterozygous for the macroH2A1.1 allele were further crossed to deleter Cre mice to generate the macroH2A1.1 ${ }^{-1-}$ (knockout, KO) mice, respectively. All mice used were obtained after eight generations of back crossing on a C57Bl/6 genetic background. Mice were bred and maintained at the EMBL Mouse Biology Unit, Monterotondo, or at Plaisant Srl (Rome, Italy), in accordance with current Italian legislation (article 9, 27 January 1992, number 116) under a license from the Italian Health Ministry. The congenic C57BL/6-Ly5.1 mice were purchased from Charles River Laboratory. C57BL/6Ly5.1/2 recipients were generated by intercrossing C57BL/6-Ly5.1 and C57Bl/6-Ly5.2 mice (Harlan, Italy).

\section{Bone marrow transplantation assays}

Radiation chimeras were generated as described [56]. For competitive transplantation assays, a 1:3 mixture of $\mathrm{BM}$ cells from the donor macroH2A1.1 $1^{\mathrm{fl} / \mathrm{fl}}$, macroH2A1.1 HET, or macroH2A1.1 KO mice $\left(\mathrm{CD} 45.2^{+}\right)$and helper WT $\left(\mathrm{CD} 45.1^{+}\right)$mice, respectively, was injected into the tail vein of the recipient $\left(\mathrm{CD} 45.1 / 2^{+}\right)$mice. For noncompetitive transplantation assays, $1 \times 10^{6} \mathrm{BM}$ cells from macroH2A1.1 ${ }^{\mathrm{fl} / \mathrm{fl}}$, macroH2A1.1 HET, or macroH2A1.1 KO mice $\left(\mathrm{CD} 45.2^{+}\right)$were injected into the recipient mice. The recipient mice were treated with Baytril (Enrofloxacin, Bayer) in drinking water $(17 \mathrm{mg} / \mathrm{ml})$ for the duration of the experiment.

\section{Statistical analyses}

Data are shown as means \pm standard error of the mean (SEM). Groups were compared with either Student's $t$ test or the non-parametric Mann-Whitney $U$ test, as appropriate, using GraphPad Prism Software (version 5.00 for Windows, San Diego, CA, USA): significance was $p \leq 0.05$. Survival analyses of mice employed the KaplanMeier estimator.

\section{Additional files}

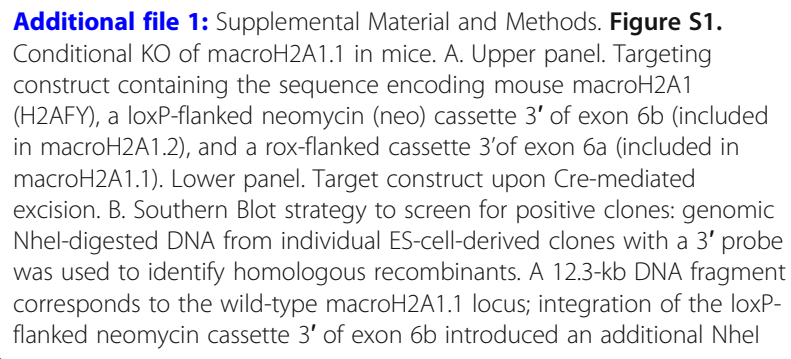

Additional file 1: Supplemental Material and Methods. Figure S1. Conditional $\mathrm{KO}$ of macroH2A1.1 in mice. A. Upper panel. Targeting construct containing the sequence encoding mouse macroH2A1 (H2AFY), a loxP-flanked neomycin (neo) cassette 3' of exon 6b (included in macroH2A1.2), and a rox-flanked cassette 3 'of exon 6a (included in macroH2A1.1). Lower panel. Target construct upon Cre-mediated excision. B. Southern Blot strategy to screen for positive clones: genomic Nhel-digested DNA from individual ES-cell-derived clones with a 3' probe was used to identify homologous recombinants. A 12.3-kb DNA fragment corresponds to the wild-type macroH2A1.1 locus; integration of the loxPflanked neomycin cassette $3^{\prime}$ of exon $6 \mathrm{~b}$ introduced an additional Nhel

site, thus increasing the size of the Nhel DNA fragment to $16.2-\mathrm{kb}$ in the targeted allele. Figure S2. Peripheral blood counts and biochemical parameters in macroH2A1.1 Fl/- and $1 \mathrm{KO}$ mice. Blood samples were collected into heparinized containers from wild type (WT), macroH2A1.1 $\mathrm{Fl} / \mathrm{Fl}$, macroH2A1.1 Fl/- and $\mathrm{KO}$ mice via tail vein. Data are expressed as mean \pm SEM. ${ }^{*} p<0.05 ;{ }^{* *} p<0.01 ;{ }^{* * *} p<0.001$ as compared to macroH2A1.1 Fl/FI. N=12-15 per each group. Figure S3. Effect of macroH2A1.1 knock/down (KD) on ribosomal protein gene expression in HL-60 and THP-1 cells. A, B. RNA was extracted from HL-60 (A) or THP-1 (B) cells stably overexpressing a vector carrying scrambled shRNA (CTL) or a vector carrying shRNA for macroH2A1.1 (KD), and processed for QPCR using specific primers against macroH2A1.1 or macroH2A1.2 transcripts. C, D. RNA was extracted from HL-60 (C) or THP-1 (D) cells stably overexpressing a lentiviral vector carrying scrambled shRNA $(\mathrm{CTL})$ or a vector carrying shRNA for macroH2A1 (KD), and processed for $\mathrm{QPCR}$ using specific primers against Rpl19, Rpl29, Rpl38, Rps15a and Rps21 transcripts. Data are presented as means relative to CTL cells, $+/-\mathrm{SD}, n=$ 4. ${ }^{* * *} P<0.001$ relative to CTL. (DOCX $680 \mathrm{~kb}$ )

Additional file 2: Table S1. Basic MDS patient/sample characteristics. Patients are classified according to the WHO classification $2016^{13}$. Excel file provided separately. MDS-SLD - MDS with single lineage dysplasia. MDS-MLD - MDS with multi-lineage dysplasia. MDS-RS-MLD - MDS with ring sideroblasts and multi-lineage dysplasia. MDS-EB-1 - MDS with excess blasts-1. MDS-EB-2 - MDS with excess blasts-2. 5q- syndrome MDS with isolated del(5q). (XLSX $56 \mathrm{~kb}$ )

Additional file 3: Table S2. List of 599 transcripts displaying $>1.5$ fold change in hematopoietic progenitor cells (HPC) isolated from bone marrow of macroH2A1.1 KO versus Fl/FI mice. (PDF $295 \mathrm{~kb}$ )

\section{Abbreviations}

BM: Bone marrow; CMP: Common myeloid progenitor; GMP : Cranulocytemacrophage progenitor; HSC: Hematopoietic stem cells; KO: Knockout; MDS : Myelodysplastic syndrome; MEP: Erythroid progenitor; RNA-Seq : RNAsequencing

\section{Acknowledgements}

We are grateful to Madeleine Teucher, Sant'Agata, Sara Cannito, Kamilla Malinowska-Ozdowy, Takis Biotech (Rome, Italy), and the HistoPathology of the VBCF (Vienna, Austria) for the technical help. We thank Prof. Andreas Ladurner (LMU, Germany) and Prof. Nadia Rosenthal (Jackson Laboratories, US) for the mentorship, and Insight Editing London for the professional editing of the manuscript.

\section{Authors' contributions}

$\mathrm{OB}, \mathrm{OLR}$, and SF performed HSC extraction, processing, and flow cytometry analyses. FN performed in vitro irradiation/DNA damage experiments and immunofluorescence. TM performed bioinformatics analyses. JK performed gene expression analyses on patient bone marrow samples. AFS designed the construct to generate KO mice. MMLP and MB performed in vitro gene expression experiments. CG, GP, GLV, VP, and LC assisted with clinical and patient data analyses. OB, CR, LK, SP, AFS, and MV conceived experiments, analyzed data, supervised experiments, and provided essential reagents, equipment, and infrastructure. MV conceived the study, directed the study, and wrote the manuscript. All authors read and approved the final manuscript.

\section{Funding}

This work was supported by the European Social Fund and European Regional Development Fund - Projects MAGNET (No. CZ.02.1.01/0.0/0.0/ 15_003/0000492) (M.V.) and EATRIS-CZ (No. CZ.02.1.01/0.0/0.0/16_013/ 0001818) (S.P.), by Italian Ministry of Education and Research grants to O.B., and by Italian Ministry of Health grant (GR-2010-2311017) to V.P. and M.V.." We acknowledge also the CF Genomics CEITEC MU support by the NCMG research infrastructure (LM2015091 funded by MEYS CR) to J.K., and the University Hospital Brno support by MH CZ - DRO (FNBr, 65269705) to J.K. and L.C. The work in L.K. group was supported by Wellcome Trust Collaborative Grant 206292/E/17/Z, the Czech Science Foundation (GACR 17-17720S), and the project LQ1605 from MEYS CR. 


\section{Availability of data and materials}

The datasets used and/or analyzed during the current study are available from the corresponding author on reasonable request.

\section{Ethics approval and consent to participate}

All samples were collected following written informed consent of the patients, in accordance with the Declaration of Helsinki, and as approved by the Ethical Committee of the University Hospital Brno.

\section{Consent for publication}

Not applicable.

\section{Competing interests}

The authors declare that they have no competing interests.

\section{Author details}

${ }^{1}$ Department of Medicine, Department of Philosophy, Social Sciences and Education, University of Perugia, Perugia, Italy. ${ }^{2}$ International Clinical Research Center, St'Anne University Hospital, Brno, Czech Republic. ${ }^{3}$ Department of Biology, Faculty of Medicine, Masaryk University, Brno, Czech Republic. ${ }^{4}$ Central European Institute of Technology, Masaryk University, Brno, Czech Republic. ${ }^{5}$ Department of Internal Medicine - Hematology and Oncology, Faculty of Medicine, University Hospital Brno and Masaryk University, Brno, Czech Republic. ${ }^{6}$ RCCS Casa Sollievo della Sofferenza, Bioinformatics unit,

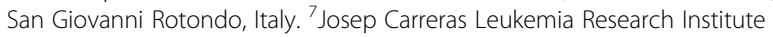
(IJC), Universitat Autònoma de Barcelona, Campus ICO-Germans Trias I Pujol, Badalona, Spain. ${ }^{8}$ Programme of Predictive and Personalized Medicine of Cancer, Germans Trias i Pujol Research Institute (PMPPC-IGTP), Badalona, Spain. ${ }^{9}$ Division of Hematology, A.O.U. Policlinico-OVE, University of Catania, Catania, Italy. ${ }^{10}$ Department of Medical and Surgical Sciences and Advanced Technologies "GF Ingrassia", University of Catania, Catania, Italy.

${ }^{11}$ Department of Biomedical and Biotechnological Sciences, University of Catania, Catania, Italy. ${ }^{12}$ Gastroenterology unit, IRCCS Casa Sollievo della Sofferenza, San Giovanni Rotondo, Italy. ${ }^{13}$ Genomics, Biotechnology Center, Center for Molecular and Cellular Bioengineering, Technische Universität Dresden, Dresden, Germany.

Received: 25 February 2019 Accepted: 12 August 2019

Published online: 22 August 2019

\section{References}

1. Milyavsky M, Gan OI, Trottier M, Komosa M, Tabach O, Notta F, et al. A distinctive DNA damage response in human hematopoietic stem cells reveals an apoptosis-independent role for p53 in self-renewal. Cell Stem Cell. 2010;7(2):186-97.

2. Kosan C, Godmann M. Genetic and epigenetic mechanisms that maintain hematopoietic stem cell function. Stem Cells Int. 2016;2016:5178965.

3. Shastri A, Will B, Steidl U, Verma A. Stem and progenitor cell alterations in myelodysplastic syndromes. Blood. 2017;129(12):1586-94.

4. Corey SJ, Minden MD, Barber DL, Kantarjian H, Wang JC, Schimmer AD. Myelodysplastic syndromes: the complexity of stem-cell diseases. Nat Rev Cancer. 2007;7(2):118-29.

5. Raza A, Galili N. The genetic basis of phenotypic heterogeneity in myelodysplastic syndromes. Nat Rev Cancer. 2012;12(12):849-59.

6. Yip BH, Steeples V, Repapi E, Armstrong RN, Llorian M, Roy S, et al. The U2AF1S34F mutation induces lineage-specific splicing alterations in myelodysplastic syndromes. J Clin Invest. 2017;127(6):2206-21.

7. Giallongo S, Lo Re O, Vinciguerra M. Macro histone variants: emerging rheostats of gastrointestinal cancers. Cancers. 2019;11(5).

8. Lo Re $\mathrm{O}$, Vinciguerra M. Histone MacroH2A1: A chromatin point of intersection between fasting, senescence and cellular regeneration. Genes. 2017;8(12)

9. Borghesan M, Fusilli C, Rappa F, Panebianco C, Rizzo G, Oben JA, Mazzoccoli G, Faulkes C, Pata I, Agodi A, Rezaee F, Minogue S, Warren A, Peterson A, Sedivy JM, Douet J, Buschbeck M, Cappello F, Mazza T, Pazienza V, Vinciguerra M. DNA hypomethylation and histone variant macroH2A1 synergistically attenuate chemotherapy-induced senescence to promote hepatocellular carcinoma progression. Cancer Res. 2016;76(3):594-606.

10. Cantarino N, Douet J, Buschbeck M. MacroH2A--an epigenetic regulator of cancer. Cancer letters. 2013;336(2):247-52.
11. Chen H, Ruiz PD, McKimpson WM, Novikov L, Kitsis RN, Gamble MJ. MacroH2A1 and ATM play opposing roles in paracrine senescence and the senescence-associated secretory phenotype. Molecular cell. 2015;59(5):719-31.

12. Lo Re O, Fusilli C, Rappa F, Van Haele M, Douet J, Pindjakova J, et al. Induction of cancer cell stemness by depletion of macrohistone H2A1 in hepatocellular carcinoma. Hepatology. 2017.

13. Park SJ, Shim JW, Park HS, Eum DY, Park MT, Mi Yi J, et al. MacroH2A1 downregulation enhances the stem-like properties of bladder cancer cells by transactivation of Lin28B. Oncogene. 2016;35(10):1292-301.

14. Pazienza V, Borghesan M, Mazza T, Sheedfar F, Panebianco C, Williams R, et al. SIRT1-metabolite binding histone macroH2A1.1 protects hepatocytes against lipid accumulation. Aging (Albany NY). 2014;6(1):35-47.

15. Rappa F, Greco A, Podrini C, Cappello F, Foti M, Bourgoin L, et al. Immunopositivity for histone macroH2A1 isoforms marks steatosisassociated hepatocellular carcinoma. PloS one. 2013;8(1):e54458.

16. Timinszky G, Till S, Hassa PO, Hothorn M, Kustatscher G, Nijmeijer B, et al. A macrodomain-containing histone rearranges chromatin upon sensing PARP1 activation. Nat Struct Mol Biol. 2009;16(9):923-9.

17. Creppe C, Janich P, Cantarino N, Noguera M, Valero V, Musulen E, et al. MacroH2A1 regulates the balance between self-renewal and differentiation commitment in embryonic and adult stem cells. Mol Cell Biol. 2012;32(8):1442-52.

18. Posavec M, Timinszky G, Buschbeck M. Macro domains as metabolite sensors on chromatin. Cell Mol Life Sci. 2013;70(9):1509-24.

19. Sporn JC, Kustatscher G, Hothorn T, Collado M, Serrano M, Muley T, et al. Histone macroH2A isoforms predict the risk of lung cancer recurrence. Oncogene. 2009;28(38):3423-8.

20. Hurtado-Bages S, Guberovic I, Buschbeck M. The MacroH2A1.1 - PARP1 Axis at the intersection between stress response and metabolism. Front Genet. 2018;9:417.

21. Makishima H, Visconte V, Sakaguchi H, Jankowska AM, Abu Kar S, Jerez A, et al. Mutations in the spliceosome machinery, a novel and ubiquitous pathway in leukemogenesis. Blood. 2012;119(14):3203-10.

22. Shirai CL, Ley JN, White BS, Kim S, Tibbitts J, Shao J, et al. Mutant U2AF1 expression alters hematopoiesis and pre-mRNA splicing in vivo. Cancer Cell. 2015;27(5):631-43.

23. Tang SH, Silva FJ, Tsark WM, Mann JR. A Cre/loxP-deleter transgenic line in mouse strain 129S1/SvImJ. Genesis. 2002;32(3):199-202.

24. Elinav E, Ackerman Z, Maaravi Y, Ben-Dov IZ, Ein-Mor E, Stessman J. Low alanine aminotransferase activity in older people is associated with greater long-term mortality. J Am Geriatr Soc. 2006;54(11):1719-24.

25. Ruhl CE, Everhart JE. The association of low serum alanine aminotransferase activity with mortality in the US population. Am J Epidemiol. 2013;178(12):1702-11.

26. Challen GA, Boles N, Lin KK, Goodell MA. Mouse hematopoietic stem cell identification and analysis. Cytometry A. 2009;75(1):14-24.

27. Kiel MJ, Yilmaz OH, Iwashita T, Yilmaz OH, Terhorst C, Morrison SJ. SLAM family receptors distinguish hematopoietic stem and progenitor cells and reveal endothelial niches for stem cells. Cell. 2005;121(7):1109-21.

28. Xu C, Xu Y, Gursoy-Yuzugullu O, Price BD. The histone variant macroH2A1.1 is recruited to DSBs through a mechanism involving PARP1. FEBS Lett. 2012; 586(21):3920-5.

29. Laurenti E, Varnum-Finney B, Wilson A, Ferrero I, Blanco-Bose WE, Ehninger A, et al. Hematopoietic stem cell function and survival depend on c-Myc and N-Myc activity. Cell Stem Cell. 2008;3(6):611-24.

30. Galili N, Qasim SA, Raza A. Defective ribosome biogenesis in myelodysplastic syndromes. Haematologica. 2009;94(10):1336-8.

31. Chou SF, Chen HL, Lu SC. Up-regulation of human deoxyribonuclease II gene expression during myelomonocytic differentiation of HL-60 and THP-1 cells. Biochem Biophys Res Commun. 2002;296(1):48-53.

32. Chen MT, Lin HS, Shen C, Ma YN, Wang F, Zhao HL, et al. PU.1-regulated long noncoding RNA Inc-MC controls human monocyte/macrophage differentiation through interaction with MicroRNA 199a-5p. Mol Cell Biol. 2015;35(18):3212-24

33. Marjanovic MP, Hurtado-Bages S, Lassi M, Valero V, Malinverni R, Delage $H_{\text {, }}$ et al. MacroH2A1.1 regulates mitochondrial respiration by limiting nuclear NAD+ consumption. Nat Struct Mol Biol. 2017.

34. Ouararhni K, Hadj-Slimane R, Ait-Si-Ali S, Robin P, Mietton F, Harel-Bellan A, et al. The histone variant $\mathrm{mH} 2 \mathrm{~A} 1.1$ interferes with transcription by downregulating PARP-1 enzymatic activity. Genes Dev. 2006;20(23):3324-36.

35. Cong R, Das S, Douet J, Wong J, Buschbeck M, Mongelard F, et al. macroH2A1 histone variant represses rDNA transcription. Nucleic Acids Res. 2014;42(1):181-92. 
36. Douet J, Corujo D, Malinverni R, Renauld J, Sansoni V, Posavec Marjanovic $\mathrm{M}$, et al. MacroH2A histone variants maintain nuclear organization and heterochromatin architecture. J Cell Sci. 2017;130(9):1570-82.

37. Boamah EK, Kotova E, Garabedian M, Jarnik M, Tulin AV. Poly(ADP-Ribose) polymerase 1 (PARP-1) regulates ribosomal biogenesis in Drosophila nucleoli. PLoS Genet. 2012;8(1):e1002442.

38. Boultwood J, Fidler C, Strickson AJ, Watkins F, Gama S, Kearney L, et al. Narrowing and genomic annotation of the commonly deleted region of the 5q- syndrome. Blood. 2002;99(12):4638-41.

39. Ou R, Huang J, Shen H, Liu Z, Zhu Y, Zhong Q, et al. Transcriptome analysis of CD34+ cells from myelodysplastic syndrome patients. Leuk Res. 2017;62:40-50.

40. Schneider RK, Adema V, Heckl D, Jaras M, Mallo M, Lord AM, et al. Role of casein kinase 1A1 in the biology and targeted therapy of del(5q) MDS Cancer Cell. 2014;26(4):509-20.

41. Schneider RK, Schenone M, Ferreira MV, Kramann R, Joyce CE, Hartigan C, et al. Rps14 haploinsufficiency causes a block in erythroid differentiation mediated by S100A8 and S100A9. Nat Med. 2016;22(3):288-97.

42. Graf T, Enver T. Forcing cells to change lineages. Nature. 2009;462(7273):587-94.

43. Hu D, Shilatifard A. Epigenetics of hematopoiesis and hematological malignancies. Genes Dev. 2016;30(18):2021-41.

44. Will B, Zhou L, Vogler TO, Ben-Neriah S, Schinke C, Tamari R, et al. Stem and progenitor cells in myelodysplastic syndromes show aberrant stage-specific expansion and harbor genetic and epigenetic alterations. Blood. 2012; 120(10):2076-86

45. Beachy SH, Aplan PD. Mouse models of myelodysplastic syndromes. Hematol Oncol Clin North Am. 2010;24(2):361-75.

46. Ades L, Itzykson R, Fenaux P. Myelodysplastic syndromes. Lancet. 2014, 383(9936):2239-52

47. Estey E, Dohner H. Acute myeloid leukaemia. Lancet. 2006;368(9550):1894-907.

48. Ruggero D, Shimamura A. Marrow failure: a window into ribosome biology. Blood. 2014;124(18):2784-92.

49. Buszczak M, Signer RA, Morrison SJ. Cellular differences in protein synthesis regulate tissue homeostasis. Cell. 2014;159(2):242-51.

50. Signer RA, Magee JA, Salic A, Morrison SJ. Haematopoietic stem cells require a highly regulated protein synthesis rate. Nature. 2014;509(7498):49-54.

51. Guimaraes JC, Zavolan M. Patterns of ribosomal protein expression specify normal and malignant human cells. Genome Biol. 2016;17(1):236.

52. Strupp C, Nachtkamp K, Hildebrandt B, Giagounidis A, Haas R, Gattermann $\mathrm{N}$, et al. New proposals of the WHO working group (2016) for the diagnosis of myelodysplastic syndromes (MDS): characteristics of refined MDS types. Leukemia Res. 2017;57:78-84.

53. Testa G, Schaft J, van der Hoeven F, Glaser S, Anastassiadis K, Zhang Y, et al. A reliable lacZ expression reporter cassette for multipurpose, knockout-first alleles. Genesis. 2004:38(3):151-8.

54. Fu J, Teucher M, Anastassiadis K, Skarnes W, Stewart AF. A recombineering pipeline to make conditional targeting constructs. Methods Enzymol. 2010:477:125-44.

55. Anastassiadis K, Fu J, Patsch C, Hu S, Weidlich S, Duerschke K, et al. Dre recombinase, like $\mathrm{Cre}$, is a highly efficient site-specific recombinase in E. coli, mammalian cells and mice. Dis Model Mech. 2009;2(9-10):508-15.

56. Sorcini D, Bruscoli S, Frammartino T, Cimino M, Mazzon E, Galuppo M, et al. Wnt/beta-catenin signaling induces integrin alpha4beta1 in T cells and promotes a progressive neuroinflammatory disease in mice. J Immunol. 2017.

\section{Publisher's Note}

Springer Nature remains neutral with regard to jurisdictional claims in published maps and institutional affiliations.

Ready to submit your research? Choose BMC and benefit from:
- fast, convenient online submission
- thorough peer review by experienced researchers in your field
- rapid publication on acceptance
- support for research data, including large and complex data types
- gold Open Access which fosters wider collaboration and increased citations
- maximum visibility for your research: over 100M website views per year
At BMC, research is always in progress.
Learn more biomedcentral.com/submissions

